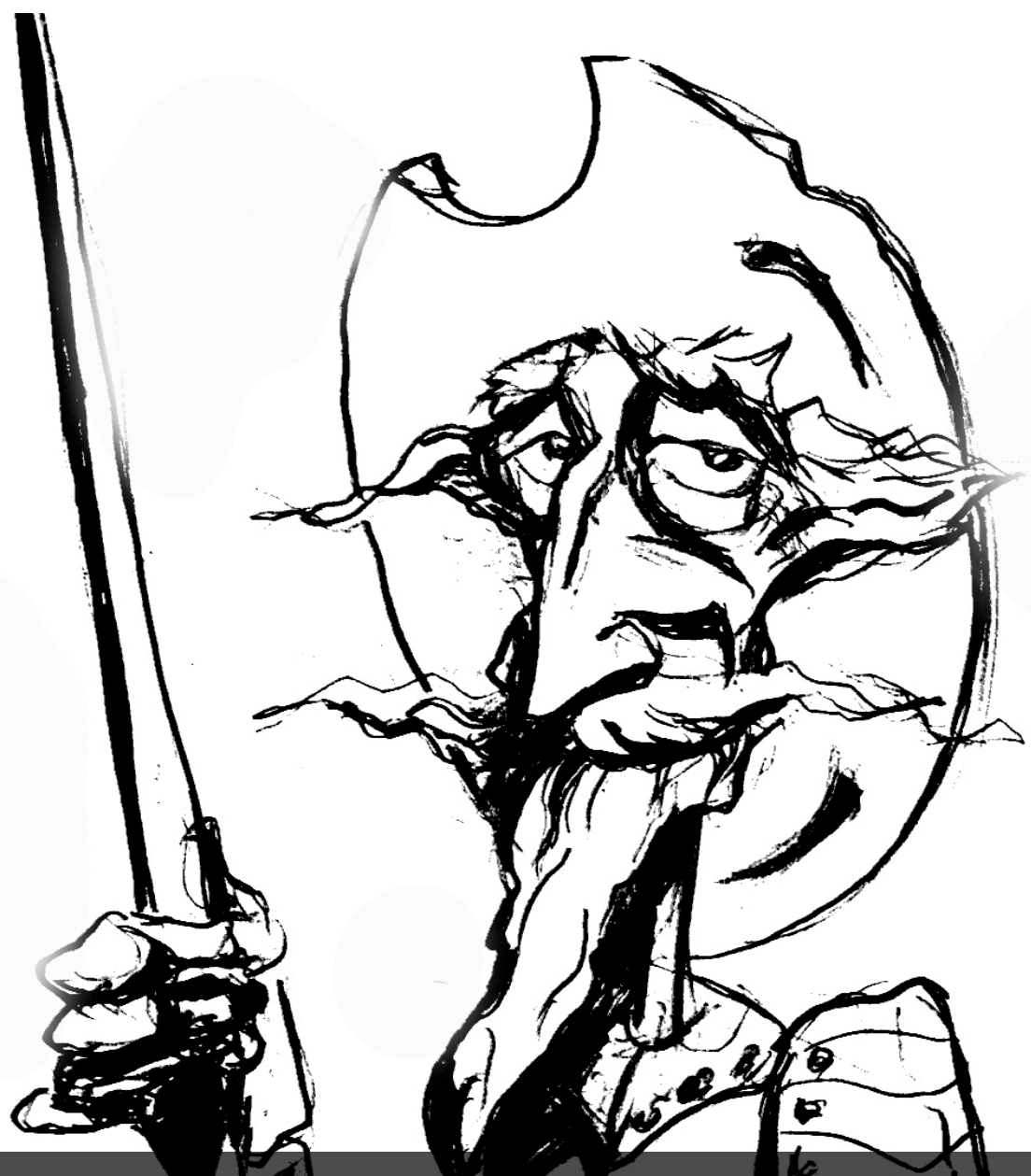

Crisis, radicalización y política en el Taller Total de Córdoba, 1970-1975.

[Juan Sebastián Malecki] 


\title{
Crisis, radicalización y política en el Taller Total de Córdoba, 1970-1975*
}

\section{Crisis, Radicalization and Politics in Cordoba's Taller Total, 1970-1975}

\author{
JUAN SEBASTIÁN MALECKI
}

\section{Resumen}

El Taller Total fue, probablemente, una de los episodios más ricos y complejos en la historia de las universidades nacionales de Argentina, en donde se superpusieron radicalización política, discusiones disciplinares y debates pedagógicos. Producto de una serie de crisis - universitaria, institucional, social, disciplinar- que se venían gestando desde tiempo atrás, el TT se presenta como un excelente caso para indagar en las relaciones que se dieron entre arquitectura y política. El presente artículo se propone una reconstrucción de los procesos que llevaron al TT así como un análisis de su dinámica, procurando avanzar sobre algunas prácticas urbano-arquitectónicas.

\section{Palabras clave}

Radicalización - Taller Total - arquitectura Córdoba - universidad

\begin{abstract}
The Taller Total was, probably, one of the richest and most complex episodes in the history of Argentinean national Universities, in which political radicalization, architectural discussions and pedagogical debates overlapped. Taller Total was the product of a series of long brewing crises involving institutions, politics, society, the university, and the discipline of Architecture itself. For those reasons, it is an excellent case to enquire about the relationship between architecture and politics. The present article aims to reconstruct the processes that led to the experience of Taller Total, as well as to analyze its inner dynamics, and to advance in the identification of some urban-architectonic practices.
\end{abstract}

\section{Key words}

Radicalization - Taller Total - Architecture Cordoba - University

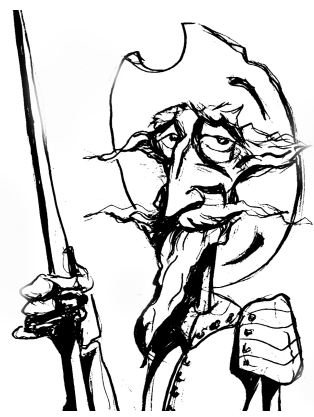

Recibido con pedido de publicación el 15 de enero de 2016

Aceptado para su publicación el 20 de marzo de 2016

Versión definitiva recibida el 16 de mayo de 2016

Juan Sebastián Malecki, Universidad Nacional de Córdoba / Consejo Nacional de Investigaciones Científicas y Técnicas, Argentina; e-mail: j.sebamalecki@gmail.com

* Agradezco los comentarios recibidos de los árbitros anónimos de la revista.

Esta obra se publica bajo licencia Creative Commons. Atribución-NoComercial-CompartirIgual 4.0 Internacional

Malecki, Juan Sebastián “Crisis, radicalización y política en el Taller Total de Córdoba, 1970-1975”, Prohistoria, Año XIX, núm. 25, jun. 2016, pp. 79-103. 


\section{Presentación}

El proceso de radicalización social y política que se desarrolló entre finales de los años 60 y mediados de los 70 afectó, con diversos grados e intensidades, a buena parte de la sociedad argentina. Algunos de los espacios donde ese proceso se sintió más fuerte -o donde tuvo su expresión más intensa- fueron los sindicatos y las fábricas, los grupos armados y las universidades. Dentro de este último ámbito, se asoció la radicalización a la difusión de nuevas perspectivas intelectuales y a la emergencia de nuevas generaciones, siendo el caso de la Universidad de Buenos Aires y más particularmente la carrera de sociología el que más atención ha recibido. ${ }^{1}$ Esto ha establecido una suerte de modelo, según el cual ha medida que las teorías de corte marxista iban sustituyendo a las de corte estructural-funcionalista, una nueva generación cuestionaba y desplazaba a los grupos modernizadores de los tempranos 60, como parte de un proceso en el que la creciente centralidad de la política implicaba una paulatina pérdida de la autonomía del campo intelectual. ${ }^{2}$ Podríamos ampliar y complejizar la mirada sobre esos años si incluyéramos a las Facultades de Arquitectura del país. Efectivamente, todavía no se ha recabado lo suficiente en el hecho de que uno de los ámbitos universitarios que mayor grado de politización y radicalización alcanzaron fueron dichas facultades, en las que, además, se llevaron adelante un drástico cambio en las formas de enseñanza disciplinar. Por caso, en agosto de 1970 se implementó el "Taller Total" (TT) en la Facultad de Arquitectura y Urbanismo (FAU) de Córdoba, expandiéndose a Rosario en 1971 y a la de La Plata unos años después. Si bien con características diferentes, en 1974 la FAU de Buenos Aires implementaba los “Talleres Nacionales y Populares" (TANAPO). Sobre la base de una propuesta pedagógica que redefinía los mecanismo de transmisión del conocimiento, que eliminaba las jerarquías docentes y que reformulaba el sistema de concursos, sostenido además por una dinámica de asambleas permanentes y de participación horizontal, el TT fue una de las experiencias de mayor radicalidad en la historia de las universidades argentinas. Pero a diferencia de la sociología, el TT no suponía deshacerse de una tradición disciplinar previa, ni se oponía a los grupos de la renovación universitaria post peronista - $\mathrm{O}$ a parte de ellos-, todo lo contrario, encontraba en parte de ese grupo una referencia central. Ello se debía, en buena medida, a que ambos compartían el suelo común de la cultura arquitectónica moderna, que le

\footnotetext{
1 Véase, por ejemplo, RUBINICH, Lucas "La modernización cultural y la irrupción de la sociología" en JAMES, Daniel (dir.) Violencia, proscripción y autoritarismo (1955-1976), NHA, IX, Sudamericana, Buenos Aires, 2003; PLOTKIN, Mariano "La cultura" en PLOTKIN, Mariano Argentina. La búsqueda de la democracia, V, Taurus, Madrid, 2012; BUCHBINDER, Pablo Historia de las universidades argentinas, Sudamericana, Buenos Aires, 2010.

2 SIGAL, Silvia Intelectuales y poder en Argentina. La década del sesenta, Siglo XXI, Buenos Aires, 2002.
} 
permitía al TT volver al planteo del compromiso social de la arquitectura introducido por las vanguardias arquitectónicas de la década del 20.

Si el clima de agitación social que se vivió en Córdoba después del Cordobazo de 1969 contribuyó a retomar en la FAU un conjunto de debates que habían surgido en los tempranos 60 -como la formación del arquitecto o su compromiso social-, lo cierto es que esta experiencia también era deudora de un debate disciplinar que, desde la segunda posguerra, venía realizando una serie de replanteos y experimentaciones respecto a las nuevas problemáticas que se habían abierto en torno a la arquitectura moderna que llevaron, en esos años, a una situación de inestabilidad. ${ }^{3}$ Así, el diálogo con las ciencias sociales, la temática del hábitat, las "megaestructuras", la autoconstrucción o la "arquitectura de sistemas" -por nombrar algunas cuestiones que tuvieron impacto en el TT- supusieron una disciplina que era tensionada desde múltiples frentes y que, para muchos contemporáneos, suponía una situación de "crisis", que los eventos en las Facultades de Arquitectura parecían confirmar. Por cuestiones de espacio, no podremos detenernos en los debates disciplinares que nutrieron al TT. Por el contrario, nos interesa preguntarnos en qué consistió el TT, cuál fue su lógica de funcionamiento, a qué nuevas prácticas dio lugar. Para ello, reconstruiremos el proceso que se dio en la FAU de Córdoba desde los 60, la situación que se abrió luego del golpe de Estado de 1966 y la crisis institucional de 1970 que condujo al TT, para avanzar luego con algunas cuestiones más específicas. Esto nos permitirá dar cuenta no solo de una experiencia poco explorada hasta el momento, ${ }^{4}$ sino también indicar la importancia que tuvo la FAU al interior de la vida universitaria así como su presencia en la ciudad de Córdoba. Nuestra hipótesis es que el TT fue el resultado de una serie de crisis -institucional, política, social, disciplinar- que, en el contexto de radicalización post cordobazo, buscó poner en el centro de discusión la función social de la arquitectura por medio de una redefinición de las formas de enseñanza.

\section{Arquitectura y sociedad en la FAU de los 60}

Como dijimos, el TT fue la resultante de una crisis institucional que se había abierto a principios de 1970, pero cuyas causas se remontan a la configuración de la FAU en los años 60 y a la intervención de 1966. Luego de la caída del peronismo, al tiempo que se reformulaba la vida universitaria, la arquitectura

\footnotetext{
${ }^{3}$ GOLDHAGEN, Sarah y LEGAULT, Réjean (Eds.) Anxious Modernism. Experimentation in Postwar Architectural Culture, The MIT Press, Cambridge, 2000; SCOTT, Felicity Technoutopias. Politics After Modernismo, MIT Press, Cambridge, 2010.

${ }^{4}$ Hasta el momento, la única publicación disponible es la de ELKIN, Benjamín Taller Total. Una experiencia educativa democrática en la Universidad Nacional de Córdoba, Ferreyra Editor, Córdoba, 2000.
} 
moderna, que había tenido una presencia conflictiva hasta el momento, se volvía hegemónica en las Facultades de Arquitectura del país. ${ }^{5}$ En ese marco, durante los años 60, en la FAU de Córdoba se fueron formando, por lo menos, dos formas de ver y entender a la arquitectura. Una de esas posturas, sostenidas por el italiano Enrico Tedeschi -docente de Teoría de la Arquitectura desde 1956-, planteaba que el problema de la "autonomía de la arquitectura" debía resolverse en el campo de la estética, lo que lo llevaba a una identificación entre arte y arquitectura, entendiendo que el arquitecto era un suerte de artista creador. ${ }^{6}$ La otra posición, defendida por un grupo heterogéneo de profesores la mayoría de ellos activos proyectistas-, sostenía la necesidad de problematizar las relaciones sociales y económicas de la arquitectura con su medio, en el convencimiento de que la arquitectura podía intervenir positivamente en los procesos de transformación social. Hasta la intervención de 1966, este último grupo estuvo a cargo de la FAU, manteniendo un perfil "progresista" -según una apreciación de la época-, llevando adelante una agenda de discusión en la que la problemática sobre la función social de la arquitectura era introducida por medio del debate sobre las formas de enseñanza de la arquitectura.

La cuestión tomó relevancia con la realización de la III Conferencia Latinoamericana de Escuelas y Facultades de Arquitectura (CLEFA) en Alta Gracia, Córdoba, en 1964. Convocada con el tema la "formación del arquitecto", el evento no solo congregó a un importante número de representantes latinoamericanos, sino que también implicó una participación masiva de profesores y alumnos de Córdoba. En los debates que se dieron es posible identificar aquellas dos posturas. Mientras Tedeschi, Marina Waisman o Raúl Bulgheroni defendían la autonomía de la forma arquitectónica, otras posturas hacían hincapié en las determinaciones sociales y económicas derivadas de la condición de países "subdesarrollados" como los latinoamericanos. Así, en la Subcomisión que trataba la "misión del arquitecto" se dio una discusión entre una posición "comprometida" con la realidad latinoamericana que sostenía que la arquitectura "no podrá transformarse sin un cambio radical" de las estructuras, propuesta por Huberto Hobbs, y otra que afirmaba que era el arquitecto el que convertía a una construcción en una obra de arquitectura. ${ }^{7}$ Pero quien dio el tono general fue Luis Rébora en su discurso de apertura -en tanto Decano y Presidente de la CLEFA-, remarcando el papel social que la arquitectura debía asumir e interrogaba a su público, citando a Tomás

\footnotetext{
${ }^{5}$ DEAMBROSIS, Federico Nuevas visiones, Infinito, Buenos Aires, 2011. Para una perspectiva más amplia, LIERNUR, Francisco La arquitectura en la Argentina del siglo XX. La construcción de la modernidad, FNA, Buenos Aires, 2008.

${ }^{6}$ MALECKI, Sebastián "Historia y crítica. Enrico Tedeschi en el proceso de renovación de la cultura arquitectónica argentina, 1950-1970" en Eadem Utraque Europa, núm. 14, Buenos Aires, 2013.

${ }^{7}$ FAU III Conferencia Latinoamericana de Escuelas y Facultades de Arquitectura, UNC, Córdoba, 1964, pp. 56-63.
} 
Maldonado, al preguntarse “ ¿hasta cuando el arquitecto va a seguir siendo juez y verdugo de quienes solo desean una vivienda para satisfacer sus necesidades y no para inmortalizar a su autor?". 8

La CLEFA instaló con fuerza el debate sobre las formas de enseñanza de la arquitectura y la inquietud por una reforma de plan de estudios, cuestiones que fueron abordadas por toda la comunidad de la FAU en tres encuentros realizados entre agosto de 1965 y febrero de 1966, convocados por el Decano Bernadino Taranto. Estas actividades se dieron en una FAU que, como dijimos, mostraba un perfil "progresista" no solo por el posicionamiento ante eventos internacionales de gran trascendencia -como la invasión norteamericana a la República Dominicana o la guerra en Vietnam- ${ }^{9}{ }^{9}$ sino también hacia dentro de la política universitaria. Por ejemplo, Rébora junto a Camilo Dagúm -Decano de la Facultad de Ciencias Económicas- fueron los únicos respaldos docentes que obtuvo el consiliario estudiantil Abraham Kozak -líder del ala izquierdista del movimiento reformista- en su enfrentamiento con el Rector Jorge Orgaz y el Decano de Derecho, Enrique Gavier. ${ }^{10}$ Más aún, luego de la renuncia de Orgaz en 1964, Arquitectura y Económicas encabezaron un frente -calificado por la prensa como "grupo renovador"-11 que logró elegir en 1965 al ingeniero Eduardo Cammisa Tecco, docente de la FAU, como nuevo Rector. Si, como señala Califa, ${ }^{12}$ hacia mediados de los 60 el proceso de modernización que atravesó la UBA desde el derrocamiento de Perón empezaba a mostrar sus límites y los principales grupos que se habían identificado con ese proceso perdían la hegemonía que habían tenido durante los Rectorados de José Luis Romero y de Risieri Frondizi, la Universidad de Córdoba, por el contrario, parecía seguir un proceso inverso, en donde los sectores más tradicionalistas fueron perdiendo peso frente a los más progresistas, que además aglutinaba a las Facultades más nuevas. Así, mientras la Revolución Libertadora puso como Rector a Agustín Caeiro, de la Democracia Cristiana, recién con Orgaz, de filiación socialista, el reformismo alcanzó plenamente el gobierno de la Universidad, pero no fue hasta la elección de Cammisa Tecco que se consolidaron los sectores que, podríamos aventurar, se encontraban a la izquierda de Orgaz y estaban más identificados con el proceso de modernización cultural.

Con el golpe de Estado de 1966 y la consiguiente intervención a las Universidades, Taranto fue desplazado por Marcelo Urrets Zavalía, hermano

\footnotetext{
8 FAU III Conferencia... cit. pp. 27-29.

${ }^{9}$ Ord. HCD $1.282(6 / 5 / 65)$ y $1.333(15 / 10 / 65)$.

${ }^{10}$ FERRERO, Roberto Historia crítica del movimiento estudiantil de Córdoba. Tomo III (1955-1973), Alción Editora, Córdoba. 2009, p. 128.

${ }^{11}$ Boletín FAU, 4/5, julio-agosto de 1965, p. 4.

${ }^{12}$ CALIFA, Juan Sebastián Reforma y revolución. La radicalización política del movimiento estudiantil de la UBA 1943-1966, Eudeba, Buenos Aires, 2014, p. 237 y ss.
} 
del Subsecretario de Gobierno de la Provincia de Córdoba, que un volante de la época denunciaba como "el partido cordobés" de la "sagrada familia". ${ }^{13}$ Pero más importante aún, un grupo numeroso de profesores -que además formaban parte de los sectores que se había nucleado alrededor de Taranto y Réborapresentaron una nota al Decano y a la prensa manifestando su decisión de no prestarse a "seguir colaborando en (...) la presunta normalización" de la universidad. ${ }^{14}$ Esto implicó su inmediata expulsión, siendo el grupo más numeroso de exonerados de la UNC, cuando no el único. ${ }^{15}$ De tal forma, la FAU se quedaba sin la mayoría de sus profesores titulares y adjuntos de Composición Arquitectónica, mucho de los cuales eran prestigiosos profesionales, con una significativa obra construida o proyectada en la ciudad, dejando a la FAU en una situación de crisis latente.

\section{El "proceso 69": crisis y radicalización en Arquitectura}

Si 1967 fue un año relativamente tranquilo, en 1968 la situación comenzó a cambiar. Durante ese año los estudiantes protagonizaron diversos enfrentamientos con el Rector y el gobierno provincial -incluyendo la toma del Comedor Universitario en apoyo a la CGTA-, aparecieron diversas coordinadoras estudiantiles -como la "Coordinadora Estudiantil en Lucha (intertendencias)" - y se consolidaron nuevas agrupaciones estudiantiles -como la Corriente de Izquierda Universitaria- que expresaban el proceso de politización que se vivía en el movimiento estudiantil. ${ }^{16} \mathrm{El}$ Cordobazo sirvió de catalizador de diversos procesos de radicalización y politización previos que se vieron intensificados. Ese clima de rebeldía y efervescencia también invadió a buena parte de la cultura arquitectónica de Córdoba y muy particularmente afectó al ámbito de la FAU. En tal sentido, la idea de un "proceso 69", según lo recuerda una de las participantes, remite a la crisis que comenzó a tomar forma ese año, pero que se extendió hasta 1970 y que tuvo un desenlace inesperado con la puesta en marcha del TT.

Para mayo de 1970, diversas instancias advertían sobre la situación conflictiva que se vivía en la FAU. Por ejemplo, una asamblea del "grupo de base de primer y segundo año" denunciaba "las serias irregularidades" de la FAU, reclamaba la derogación del "Test de ingreso", exigía la anulación del examen de Geometría Descriptiva y demandaba la remoción de las cátedras de

\footnotetext{
13 "Sepa el pueblo de Córdoba quien es quién en la sagrada familia", citado en FERRERO, Roberto Historia crítica, cit., pp. 212-13.

${ }^{14}$ Los Principios, Córdoba, 6/10/66.

${ }^{15}$ No hay estudios que acrediten cuántos cesanteados hubo en la UNC. En la FAU pudimos comprobar 27 profesores exonerados y 5 suspendidos temporalmente: 5 Titulares; 14 Adjuntos; 9 JTP. Resolución Decanal (RD) 174 (11/10/66).

${ }^{16}$ FERRERO, Roberto Historia crítica, cit., pp. 188-89.
} 
Plástica IV y Composición IV. ${ }^{17}$ A la par del reclamo de los estudiantes, el "Frente de arquitectos de Córdoba" se manifestaba en contra de los concursos docentes que había llamado la Facultad. ${ }^{18}$ Justamente los problemas con las cátedras de Plástica IV y Composición IV son indicadores de la situación de confusión que reinó en la primera parte del año 1970, como prolongación de la situación del año anterior. Por un lado, un grupo de alumnos elevaron quejas al Decano y al Consejo Académico -incluido un pedido de juicio académico-, sosteniendo que no estaba claro el programa de la materia ni las formas de evaluación y que los docentes incurrían en repetidas ausencias en el dictado de clases. ${ }^{19}$ Por otro lado, también fue en esas materias donde se intentó, según recuerda un estudiante, una reformulación en la forma de enseñanza de la arquitectura. Si la práctica corriente era trabajar sobre un "programa arquitectónico" para un sitio determinado, la cátedra cuestionada -a cargo de Santiago Kunzle- había propuesto como tema el "turismo" para el curso de 1969, pidiéndoles a los estudiantes que llevaran adelante una investigación en grupo. ${ }^{20} \mathrm{Si}$ bien este primer intento de una aproximación diferente a la arquitectura parece no haber tenido mucho éxito, contrasta con la otra cátedra de Composición IV que había elegido como tema las "salas de concierto", lo que en un clima de creciente politización era visto como alejado de los problemas reales. Según recuerda un estudiante de la época: "queríamos participar en la elección del tema de diseño, reconocer un usuario real". ${ }^{21}$ En un sentido parecido, en el marco del décimo congreso de la Unión Internacional de Arquitectos, se llevó adelante en 1969 el III Encuentro Internacional de Estudiantes de Arquitectura en Buenos Aires, convocado bajo el tema de la "vivienda de interés social". Como era práctica corriente, se realizó un concurso de proyectos para estudiantes del último año. En Córdoba, el Taller de Tesis estaba a cargo de Tedeschi, quien rehusó tomar esa temática, según recuerda Arquímedes Federico, que cursaba la materia en 1968. Teniendo en cuenta el interés que despertaba en los estudiantes, Manuel Revol -socio del estudio de Taranto, Hobbs y Díaz- decidió crear una cátedra paralela para quienes quisieran presentarse al concurso. El grupo de Federico realizó una propuesta siguiendo la metodología de diseño que proponía Christopher Alexander. ${ }^{22}$ Finalmente, uno de los trabajos de dicho taller consiguió la tercera mención en el concurso nacional, en el cual, según el jurado, abundaban las citas marxistas que, sin embargo, no se veían reflejadas en la propuesta de diseño. ${ }^{23}$

\footnotetext{
${ }^{17}$ La Voz del Interior, Córdoba, 7/5/70.

${ }^{18} \mathrm{La}$ Voz del Interior, Córdoba, 2/4/70

${ }^{19}$ Córdoba, Córdoba, 7/5/70.

${ }^{20}$ Entrevista Néstor Aquilante, 20/2/13. Publicación: Cátedra Composición Arquitectónica IV:

"Informe". Investigación sobre turismo. Primera Parte", FAU, Córdoba, 1969, Grupo 4-C.

${ }^{21}$ Entrevista Arquímedes Federico por parte de Elkin, ELKIN, Benjamín Taller Total, cit. p. 125.

22 Entrevista Arquímedes Federico (10/3/13).

${ }^{23}$ Summa, núm. 22, Buenos Aires, 1970, p. 43.
} 
En este clima de crecientes enfrentamientos, el Decano Rogelio Luque puso en funcionamiento el "Consejo Académico" -contemplado en la ley universitaria 17.245 de 1967-, en un intento infructuoso por controlar la situación que se vivía en la Facultad. ${ }^{24}$ Los intentos del Consejo para encaminar su funcionamiento resultaron contraproducentes. Esto determinó que este terminara siendo asociado a un modelo de Facultad contra el cual se propuso la creación del TT, quedando dos nombres identificados al mismo: el de Waisman y Tedeschi. Mientras Waisman fue elegida Vice-Decana en abril de ese año, ${ }^{25}$ Tedeschi fue nombrado parte del Equipo Director que debía poner en funcionamiento los "Talleres verticales".

Entre abril y agosto de 1970, las diferentes iniciativas planteadas por el Consejo no hicieron más que agravar la situación en la FAU, llevando a un enfrentamiento entre este, un grupo de profesores asistentes y los estudiantes. Para junio, todavía no habían comenzado las clases en las materias de Composición Arquitectónica y allí donde lo habían hecho, se habían visto inmersas en diversos problemas. Según el Decano, las clases en Composición empezarían en septiembre de ese año ya que todavía no se había conformado el equipo docente de los Talleres Verticales. ${ }^{26}$ Esta situación generó una división por semestre entre materias "teóricas" y las de "taller" que, en las apreciaciones de la época, fueron asimiladas a la existencia de dos grupos de docentes, el primero de los cuales estaba a cargo de la FAU. ${ }^{27}$

Efectivamente, en la sesión del primero de junio, el Consejo Académico aprobó la Ordenanza 1/70 en la que se establecía un reordenamiento de las cátedras de Composición -de la II a Tesis- que dependerían de un Departamento de Composición, a cargo de un Equipo Director, dividido en tres talleres. ${ }^{28}$ Los Talleres Verticales habían aparecido en Rosario y Buenos Aires como parte del proceso de renovación disciplinar en la universidad post peronista, ligado al grupo de arquitectos modernos cercanos a la oam y la revista nv nueva visión de Tomas Maldonado, como J. M. Borthagaray, F.

\footnotetext{
${ }^{24}$ Integrado por: Edmundo Arias, Pier Baldaccini, Raúl Bulgheroni, Guillermo Fuchs, Marina Waisman, Juan Tumosa y Miguel Ángel Roca. Libro de Sesiones del Consejo Académico (LSCA) del 10/4/70.

${ }^{25} \mathrm{La}$ Voz del Interior, Córdoba, 21/4/70; RD 9/70 (17/4/70).

${ }^{26}$ LSCA, sesión del 12/6/70, folio 9.

${ }^{27}$ Justamente esta apreciación se recoge en la introducción al Libro mostaza en el que se traza un breve resumen de la situación que se vivió en la FAU que condujo al TT: "Constituido el Consejo Académico en 1969, dicta la ordenanza N 1/70, la que traduce claramente el pensamiento de sus integrantes al respecto. En la práctica se dispone la división del año lectivo en dos cuatrimestres: en el primero se desarrollarán exclusivamente las asignaturas 'teóricas' y en el segundo las de 'taller'. Se acentúa así la dicotomía. Composición Arquitectónica y Urbanismo quedan decididamente escindidas de las restantes asignaturas y se revive así la vieja y casi superada disociación" en: Libro mostaza, FAU, Córdoba, 1971, pp. 2-3.

${ }^{28}$ LSCA, sesión del 1/6/70, folio 6. No fue posible encontrar la Ordenanza 1/70.
} 
Ibarlucía, C. Méndez Mosquera, J. Le Pera, entre otros..$^{29}$ Pero si en estos casos las experiencias fueron exitosas, se debió, en buena medida, al prestigio del que gozaban sus responsables, ya que su concepción descansaba en una idea de transmisión del maestro a los alumnos. En Córdoba, por el contrario, quienes quedaron al frente, o no gozaban de las simpatías políticas que el momento requería, como Tedeschi, o no tenían un reconocimiento profesional suficiente, por lo menos no tanto como quienes habían sido cesanteados en 1966. Y esto estaba claro no solo para un grupo importante de docentes de la Facultad -la restitución de los cargos académicos de aquellos fue uno de los primeros reclamos del TT-, sino que también lo expresaba una revista cultural de amplia circulación como Jerónimo: "es sabido que, hasta antes de 1966, la cátedra de Composición (...) cobijaba a un equipo de vanguardia de la Universidad cordobesa. Alrededor de Rébora, Taranto y otros proliferó una actitud 'urbanista', preocupada por investigar las condiciones sociales del hábitat", para sugerir que detrás de la propuesta de los Talleres Verticales "se filtraba la influyente sombra de Enrico Tedeschi". ${ }^{30}$

Es imposible determinar si, como acusaba Jerónimo, la idea de los Talleres Verticales había sido propuesta por Tedeschi. Pero lo cierto es que el Equipo Director estuvo compuesto por él, Héctor Moyano y Revol, además de Miguel Ángel Roca, Rafael Mansilla y Edgardo Nizzo. Urrets Zavalía fue designado como coordinador del ciclo Básico. ${ }^{31}$ Waisman, Daniel Moisset de Espanes, Lázaro Devoto y Nicolás White se incorporaron posteriormente. ${ }^{32}$ La composición del equipo era de por sí heterogénea: mientras Revol y Tedeschi eran los que tenían mayor prestigio como arquitectos, Waisman se dedicaba a la historia, Nizzo y Roca recién comenzaban sus carreras, mientras que el resto no tenían una trayectoria profesional destacada. Pero la integración ideológica también era dispar: Tedeschi, Waisman y Urrets Zavalía representaban a los sectores liberal/conservador, mientras que Revol y Nizzo a los progresistas. Con todo, el Equipo Director duró poco y los Talleres Verticales nunca llegaron a implementarse. El 24 de junio de 1970 el Consejo aceptó las renuncias del Equipo Director: Tedeschi alegó problemas de disponibilidad, Moyano razones particulares de salud, mientras Revol sostenía que era "imposible un trabajo coordinado en el mencionado Equipo". ${ }^{33}$

\footnotetext{
29 DEAMBROSIS, Federico Nuevas visiones, cit., p. 156.

30 “Universidad. Las aguas bajan turbias", en Jerónimo, núm. 23, Córdoba, 1970, p. 44.

${ }^{31}$ RD núm. 28 (5/6/70).

32 RD núm. 32 (19/6/70).

${ }^{33}$ LSCA, sesión del 24/6/970, folio 6.
} 


\section{Crisis institucional en la FAU}

Para dar cuenta del clima de tensión, de los grupos involucrados, de las posiciones sostenidas y de las condiciones en que fue redactado el proyecto del $\mathrm{TT}$, nos detendremos en los dos meses previos al mismo. Se podría decir que la crisis final que condujo al TT se inició en la sesión del Consejo del 29 de junio de 1970. En esa sesión, los estudiantes de Tesis manifestaron un total rechazo a los talleres verticales y a los que habían quedado asociados a ellos: "desde hace tiempo la Facultad se ha dedicado a orquestar un concepto académico (...) que apunta a promover profesionales consustanciados con el sistema y al servicio de las clases dominantes". ${ }^{34}$ El consejero Tumosa, por su parte, advertía sobre la situación en que se encontraba la Facultad: "nos debatimos, sin embargo, en una lucha entre docentes y alumnos y ahora agravada la situación por la lucha entablada entre el cuerpo docente y el Consejo Académico". ${ }^{35}$

En la reunión siguiente se trataron los incidentes entre los estudiantes y la policía que tuvieron lugar en la FAU el 30 de junio y el 2 de julio; un petitorio de otro grupo de estudiantes; y se aprobó una resolución en la que se declaraban las intenciones de las autoridades de la Facultad para llevar adelante una gestión de transición pero que, ante los reiterados hechos de violencia, advertían sobre la posibilidad de la pérdida del año lectivo. ${ }^{36} \mathrm{El} 17 \mathrm{de}$ julio, Tumosa -una de las voces críticas del Consejo- presentaba su renuncia, en la que se dejaba ver la polarización que se había alcanzado: "los hechos que en la Facultad desde hace un tiempo se vienen sucediendo, no permiten presuponer actualmente que tan grave situación pueda corregirse", para agregar que "el Consejo Académico carece de justa representatividad de los sectores más numerosos y en consecuencia pocos adhieren a él. En cambio, lo convierten en el responsable de la crítica situación presente" ${ }^{37}$

En un intento por retomar el control, el Consejo hizo suya una resolución presentada por los profesores de Composición y declaró en "estado de asamblea permanente" a todos los docentes de esas materias. ${ }^{38}$ Pero la situación no hizo más que agravarse. A finales de julio se redactaron dos propuestas para reformular el Plan de Estudio. ${ }^{39}$ Según el relato de Juan Carlos Fontán, una de las propuestas fue hecha por un grupo de unas quince personas -entre ellos, Fontán, Carlos Gómez, “Tito” Garimano, Mauro Pistorio, Ricardo Veteri- en la

\footnotetext{
${ }^{34}$ LSCA, sesión del 29/06/70, folio 3.

35 LSCA, sesión del 29/06/70, folio 4.

36 LSCA, sesión del 3/07/70, folio 10. Resolución 42 (3/7/70).

${ }^{37}$ LSCA, sesión del 17 /07/70, folio 10.

38 Res. núm. 56 (24/7/70).

39 Es difícil establecer la fecha exacta. El Consejo Académico tiene noticias de la propuesta en la sesión del 29 de julio, mientras que en una mesa redonda de 1973, Veteri indica que las mismas fueron realizadas en asamblea los días 13 y 15 de agosto, ver: El Taller Total y su análisis. Primera Mesa redonda, FAU, Córdoba, 1973, p. 14.
} 
empresa constructora Urcon de Pistorio, con la ayuda de las pedagogas Justa Espeleta y Marta Casarin. La otra fue redactada, entre otros, por Edgardo Nizzo, Osvaldo Ramacciotti y Villada. ${ }^{40}$ De acuerdo a las observaciones de Nizzo y Fontán, las diferencias entre ambas estaban en la radicalidad del planteo del grupo de Fontán, que apuntaba a una reformulación "total". Cuando las dos propuestas fueron presentadas en una asamblea de profesores, Nizzo y su grupo retiraron la suya, apoyando la de Fontán. ${ }^{41}$ En la sesión del 29 de julio no solo se trató la nota de un grupo de profesores que solicitaba la reincorporación de los profesores cesanteados en 1966, sino que la mayor discusión giró en torno a esta nueva propuesta de los Profesores Asistentes de Composición.

Para agosto de 1970 la situación era insostenible. A las presiones de los estudiantes y de los grupos docentes, también se le sumaba la del "Frente de Arquitectos de Córdoba", un nucleamiento que replicaba en la ciudad el que se había conformado hacia 1968 a nivel nacional. Aunque no tenemos mayores detalles sobre el Frente, al parecer tuvo su origen en una reunión en la Universidad de Tucumán con la confluencia de varios grupos que venían sosteniendo discusiones en torno al compromiso social de la arquitectura, en base a lecturas de Henry Lefebvre, Manuel Castells y Roberto Segre, y cuyos referentes eran Marcos Winograd, Paco García Vázquez y Víctor Pelli. Como parte de ese Frente, se formó en Córdoba el "grupo del hábitat", integrado, entre otros, por Dora Aguad, Aristóbulo Peralta, "Chiqui" Edith Peralta, Iván Baigorria y Federico Larraqui. ${ }^{42}$ Algunos de ellos, además, militaban en el Movimiento de Liberación Nacional. En agosto de 1970 el "grupo del hábitat" y la CIU organizaron un encuentro para discutir sobre "Hábitat y política". Allí se identificaba la crisis de la enseñanza de la arquitectura con la crisis de los países "dependientes" y del sistema capitalista en general. Según la reseña de La voz del interior "tras los velos de la técnica y el arte de la arquitectura existe un mundo social que hay que descubrir, un 'sistema de explotación', al servicio del cual los arquitectos trabajan, den cuenta de ello o no". ${ }^{43}$

Además de estas actividades, el Frente también tomaba posición sobre la que pasaba en la FAU. Conviene detenerse brevemente en sus consideraciones. Para el Frente, la crisis en la Facultad no era una crisis "formal", sino de fondo, ya que la enseñanza partía de la premisa de que "los sistemas socio-económicos y políticos son hechos inalterables". Ante ello, sostenían, los estudiantes

\footnotetext{
${ }^{40}$ Entrevista del autor con Juan Carlos Fontán (26/2/13).

${ }^{41}$ Entrevista del autor con Juan Carlos Fontán (26/2/13). Entrevista del autor con Edgardo Nizzo $(1 / 3 / 13)$. En las actas de la sesión del 29 de julio, se menciona que la primera propuesta llevaba quince firmas mientras la segunda nueve y que ambas fueron unificadas en su aspecto operativo. LSCA, sesión del 29/7/70, folio 6.

42 Entrevista del autor con Dora Aguad (21/2/13), integrante del Frente.

${ }^{43}$ La Voz del Interior, Córdoba, 14/8/70.
} 
"pretenden que los programas se estructuren en base a las necesidades sociales". Estas demandas se planteaban a la luz del reclamo de "profesionales que además de conciencia técnica tengan conciencia social". Para el Frente, los talleres verticales implicaba una regresión ya que, si estos habían supuesto un avance en los tempranos 60, en el contexto de radicalización de los 70, debía "quedar bien claro (...) que si esa unificación del conocimiento [...en los talleres verticales] no va acompañada de un cuestionamiento a la irracionalidad, e injusticia de este sistema de explotación, queda nomás integrado al marco teórico de las necesidad del sistema y de espalda a la realidad". ${ }^{4}$

En este contexto, el Consejo entró en sesión permanente el 7 de agosto de 1970. ${ }^{45}$ Para el 22, el Consejo describía la situación anárquica de la Facultad y su impotencia por encontrar una salida. Allí se invocaba la "interrupción permanente de la actividad académica a través de asambleas, 'tomas' de la Facultad y continuo estado de agitación" que se agregaba a la renuncia del equipo director y al cuestionamiento al Plan de Estudios. Pero lo más grave parecía ser el "modo operativo propuesto" por algunos docentes que se ha "transformado en una asamblea permanente de alumnos y algunos docentes creando un clima de intranquilidad y subversión manifiesta". Ante esta situación, el 24 de agosto el Consejo cerró la Facultad, ${ }^{46}$ reabriéndola el $27 .{ }^{47} \mathrm{Al}$ día siguiente, llamaba a concurso de profesores, disponía la creación de una comisión para reorganizar las materias de Composición y se comprometía a renunciar cuando todo esto estuviera realizado. ${ }^{48}$ Pero ya era tarde: el 31 de agosto se llevó adelante una sesión secreta en el Consejo Superior en donde se leyeron las notas de renuncia de todos los miembros del Consejo Académico y la del Decano, Rogelio Luque. Al día siguiente se declaró intervenida la Facultad, nombrando a Juan Carlos Fontán como Decano Interventor. ${ }^{49}$

Mostrando la importancia que había adquirido la Facultad en la ciudad, el diario La voz del interior se hizo eco de lo que allí pasaba, sosteniendo que la crisis en Arquitectura que "se remonta prácticamente al año 1966 (cuando fueron diezmados los mejores cuadros docentes luego de la intervención a las universidades nacionales) no podía resolverse con medidas de emergencia y puramente administrativas". La nota del diario informaba además de la asamblea de estudiantes, en la que se pedía la inmediata puesta en funcionamiento de los talleres verticales, se invitaba a los profesores a coordinar las acciones con los estudiantes, se llamaba a una movilización frente

\footnotetext{
${ }^{44}$ La Voz del Interior, Córdoba, 27/8/70.

${ }^{45}$ El Consejo estuvo reunido el 20, 22, 27 y 28 de agosto de 1970.

46 Res. núm. 63 (22/8/70).

47 Res. núm. 64 (27/8/70).

48 Res. núm. 65 (28/8/70).

${ }^{49}$ LAHCS, sesión secreta del 31/8/70, Acta núm. 22; RR 592 (1/9/70, tomo III); Expediente 98482/70 (lamentablemente fue imposible acceder a dicho expediente).
} 
al Rectorado y se exigía la realización de concursos para todos los cargos docentes. ${ }^{50} \mathrm{El}$ dato es revelador de tres cuestiones: el TT no fue una propuesta estudiantil ni era parte de sus reclamos -aunque luego le dieran un respaldo decisivo-; el proyecto que iba a ser la base del TT tuvo una circulación restringida en la FAU; la designación de Fontán y la puesta en marcha del TT tomó por sorpresa a buena parte de la comunidad de la Facultad.

Ahora bien, la rápida resolución de la crisis en Arquitectura trascendió al ámbito universitario, mostrando hasta qué punto la situación preocupaba a las autoridades provinciales. Según Fontán, en una reunión en su casa en la que se encontraban Pistorio, Gómez y Hugo Taboada -quien había sido intendente de Córdoba entre 1969 y 1970 y tenía fluidos contactos con sectores de las fuerzas aéreas-, este le propuso que asumiera como Decano, en tanto tenía "los antecedentes más limpios para los militares". La primaria hecha en el colegio La Salle y la secundaria en el Liceo militar le aseguraban un perfil adecuado a los ojos de las autoridades, que se sumaba al reconocimiento profesional logrado con el proyecto para la terminal de colectivos de Córdoba de 1970. A ello se le sumaba que sus compromisos políticos no iban más allá de una identificación con el peronismo. Al consultarlo con Gómez, referente del Partido Comunista Revolucionario en la Facultad, este le aseguró su apoyo. ${ }^{51}$ Esta información es parcialmente corroborada por Jerónimo:

"sin duda influyó en Olsen Ghirardi [el Rector], para su decisión, el hecho de que Fontán sea bien mirado por colegas y alumnos, en mérito a su capacidad profesional y al preocupado interés que demostrara en reiteradas oportunidades como estudiante primero, y como profesor después, por los problemas casi insolubles de la Facultad. Estas cualidades fueron, por otra parte, las que reclamó Bernardo Bas del hombre necesario para ese puesto, porque el gobernador tuvo una participación más activa y muy directa en el principio de solución logrado en Arquitectura: mantuvo reuniones con el rector, con profesores, con arquitectos de diferentes tendencias, como Villada y Taboada, y al fin recibió, conforme, el nombramiento de Fontán". ${ }^{52}$

Pero este clima de agitación y radicalización, como señalamos al principio, no era exclusivo de Córdoba, sino común al resto de las Facultades de Arquitectura. Tal era la virulencia y el dramatismo que en ellas se vivía, que un editorial de Nuestra arquitectura se preguntaba en 1971: “¿La facultad está en

\footnotetext{
${ }^{50}$ La Voz del Interior, Córdoba, 1/9/70.

51 Entrevista del autor con Juan Carlos Fontán (26/2/13).

52 “Córdoba. Setiembre por todos lados” en Jerónimo, núm. 27, Córdoba, 1970, p. 14.
} 
crisis? ¿La arquitectura está en crisis? ¿El país está en crisis?”. ${ }^{53}$ Summa, por su parte, se hacía eco de una "profesión en crisis" al publicar un estudio en el que daba cuenta de la condición ocupacional de los arquitectos. ${ }^{54}$ Pero esta situación no era preocupación exclusiva de los arquitectos, la revista Los Libros dedicaba un número entero en noviembre de 1971 a la problemática universitaria, en la que arquitectura tenía una presencia central, con las experiencias que se estaban desarrollando en Córdoba y Rosario -en donde comenzaba a vivirse un proceso similar al del TT. ${ }^{55}$ Incluso Panorama se mostraba interesada por los conflictos en la FAU y por las nuevas perspectivas pedagógicas que allí se abrían. ${ }^{56}$

Antes de avanzar con la dinámica de funcionamiento del TT, conviene detenerse brevemente en lo que ocurrió en Buenos Aires, ya que nos permitirá mostrar un marcado contraste con la experiencia cordobesa. Lamentablemente no contamos con estudios específicos sobre lo que se conoce como los TANAPO. Pero según la información disponible, desde 1971 la FAU de Buenos Aires sufría un conflicto alentado por los estudiantes y los profesores auxiliares que se extendió durante todo 1972. De acuerdo a Jaime Sorín, en 1973 se crearon distintas "unidades pedagógicas" que, de alguna manera, fueron un preámbulo de los TANAPO que se organizaron en 1974 durante el Rectorado de Rodolfo Puiggrós. ${ }^{57}$ Los TANAPO consistían en una estructura vertical de cinco talleres que funcionaban con dos titulares: "uno con experiencia profesional y uno que venía de la política", 58 en una Facultad que estaba dominada por los diferentes grupos del peronismo de izquierda. De acuerdo a Justo Solsona, el Decano en ese momento -Alfredo Ibarlucía- lo nombró a él y a Juan Molina y Vedia como "conductores generales" de los TANAPO, cuya tarea consistía en "discutir con los titulares (...) los temas a desarrollar en los ejercicios de diseño". ${ }^{59}$ Para 1975, con la avanzada reaccionaria del Ministro Oscar Ivanissevich, la experiencia se dio por concluida. De tal manera, y de una forma un tanto apresurada, podríamos aventurar que los TANAPO tuvieron una existencia muy corta -de un año- y su funcionamiento respondía a una estructura vertical -posiblemente heredada de los talleres verticales. Si bien la participación estudiantil fue importante -Solsona recuerda que en algunos talleres se implementó la autoevaluación estudiantil- no parecen haber intervenido directamente en el

\footnotetext{
${ }^{5}$ Nuestra arquitectura, núm. 474, Buenos Aires, 1971, p. 3.

54 Summa, núm. 84, Buenos Aires, 1974.

55 Los Libros, núm. 23, Buenos Aires, 1971.

56 PÉREZ GAUDIO, S. y GOSMAN, L. "Taller Total: el fin del verticalismo", en Panorama, Buenos Aires, 24 de marzo de 1972.

${ }^{57}$ Entrevista de Juan Molina y Vedia a Jaime Sorín (16/6/05). Véase también las entrevistas a Jorge Moscaro y Rolando Schere (3/9/04). Las mismas pueden consultarse en: http://www.archivosdar.com.ar (visitado el 16/7/14).

58 Entrevista de Juan Molina y Vedia a Jaime Sorín (16/6/05).

59 SOLSONA, Justo Justo Solsona. Entrevista. Apuntes para una autobiografía, Infinito, Buenos Aires, 1997, p. 99. Todas las citas de Solsona fueron extraídas de esta entrevista.
} 
gobierno de la FAU. Por último, la experiencia estuvo impulsada por diversos grupos peronistas -Solsona indica que fueron esos grupos los que lo invitaron a sumarse a la FAU-, que corrieron con una suerte similar a la de la izquierda peronista luego de la muerte de Perón. El contraste con el TT no puede ser más marcado. Dicho de forma sintética: el TT se pensó, justamente, en oposición a las estructuras verticales, en el que la integración vertical y horizontal se correspondió con una abolición de las jerarquías docentes. El mismo fue propuesto, además, por un grupo de docentes auxiliares y luego sustentado por el movimiento estudiantil. Asimismo, su funcionamiento en base a asambleas y coordinadoras de docentes y estudiantes supuso una participación masiva de las "bases". Su duración -si se quiere también corta- se prolongó por cinco años $\mathrm{y}$ tanto en su formulación como en su funcionamiento en los talleres y en las coordinadoras tuvieron una gravitación importante diversas corrientes políticas por lo que no pudo ser adscripto a ninguna de ellas en especial.

\section{El Taller Total}

Designado como Decano, la primera medida de Fontán fue aprobar la Ordenanza 2/70, que ponía en funcionamiento al TT. Si, como recuerda un estudiante de la época, el TT los "agarró por sorpresa", 60 lo cierto es que "en un día se puso en funcionamiento todo" como señala Nizzo. El TT fue una apuesta de máxima, era "todo o nada" según Aguad. ${ }^{61}$ Así, la Facultad entraba en una actividad frenética ante lo que se suponía un cambio total de las estructuras institucionales y pedagógicas. Reuniones, encuentros, asambleas, escritos, publicaciones, traducciones, propuestas. Todo sucedía en la FAU, todo de prisa. Puesta en funcionamiento la Ordenanza 2/70, comenzó un proceso de prueba y error en el que se fue normativizando la estructura pedagógica e institucional de la Facultad, que afectó a todos los órdenes de funcionamiento, desde la división por materias, que pasó a comprender áreas de conocimiento, a la carrera docente, que fue reformulada íntegramente. En ese sentido, es importante señalar el intento de sistematizar la experiencia y de elaborar un ordenamiento institucional que le correspondiera, más aún en el contexto interno de constantes asambleas y discusiones que fue uno de sus rasgos característicos. A continuación nos proponemos analizar parte del funcionamiento y de la dinámica del TT.

En octubre de 1971 se publicó el llamado "Libro Mostaza" -en referencia al color de sus tapas- que sintetizaba la experiencia acumulada hasta ese entonces y definía el marco institucional y organizativo en el que se estaba desarrollando el TT. Sin dudas el documento más importante elaborado por el TT, en él se establecía el encuadre general de la propuesta. Tres cuestiones

\footnotetext{
60 Entrevista del autor realizada el 18/07/13.

${ }^{61}$ Entrevista del autor con Dora Aguad y "Yeye" Bari realizada el 21/02/13.
} 
merecen ser destacadas: la crítica al rol profesional, un posicionamiento respecto a las formas de enseñanza y una definición sobre la función de la arquitectura.

En el Libro Mostaza se sostenía que el TT se oponía a dos tipos de profesionales que se habían vuelto hegemónicos en las universidades. Por un lado, el "modelo" europeo o norteamericano de formación "enciclopédicoesteticista" -señalaban- "no tiene cabida en el marco de las urgencias de un país subdesarrollado, dependiente, crecido 'hacia fuera' casi despoblado, regionalmente desequilibrado, industrialmente incipiente y básicamente agropecuario". Pero su opuesto, proseguían, de aparición más reciente pero no por eso "menos disociado del país 'real", era el profesional "tecnocráticoeficientista, que trasplanta concepciones y técnicas difundidas en sociedades con otro estado de madurez científico-técnica". ${ }^{62}$ Además del vocabulario "dependentista" -de amplia circulación en la época-, la posición respecto al "profesional tecnócrata" retomaba parte de las críticas que el movimiento estudiantil había hecho al "cientificismo" -por su disociación entre técnica y política- en los años 60,63 mientras que el rechazo al modelo "esteticista" tenía como principal referente a Tedeschi y su identificación del arquitecto con el artista.

El TT se proponía, además, sostener un tipo de aprendizaje que dejara atrás las formas tradicionales de enseñanza en el que se considera al alumno un sujeto pasivo:

"la tradicional forma académico-mesiánica, como relación entre el Maestro, ente activo, y el alumno, ente pasivo y receptor. Esta estructura, carente de ambiciones y de estímulos, es un ordenamiento ficticio que lleva a la enseñanza a la condición de mera 'ceremonia'"'.64

La presencia de un grupo importante de pedagogas en el TT permite situar la experiencia dentro de un campo más vasto de replanteos y reformulaciones que se venían realizando desde los tempranos 60 pero que, por cuestiones de espacio, no podrán ser tratadas. De cualquier manera, el ingreso al TT de seis pedagogas en septiembre de 1970 contribuyó con un discurso sobre el proceso pedagógico que ponía el acento en el carácter activo y participativo de los sujetos de aprendizaje, aunque su incorporación se haya producido una vez comenzado el TT y su interacción haya sido con los docentes y no en el taller. El grupo estuvo integrado por María Saleme de Burnichón,

\footnotetext{
62 Libro Mostaza, cit., p. 6.

${ }^{63}$ CALIFA, Juan Sebastián Reforma y revolución, cit.

${ }^{64}$ Libro Mostaza, cit. p. 6.
} 
Justa Ezpeleta, Marta Casarini, Alicia Carranza, Susana Barco y Lilian Fandiño. ${ }^{65}$

Las críticas a la formación profesional junto a las propuestas de una pedagogía renovadora se superpusieron a los tiempos propios de la disciplina arquitectónica. Sin poder explayarnos en el tema, se puede decir que en la fundamentación del TT emergían con fuerza algunas de las derivas de la enseñanza de la arquitectura en clave moderna, que retomaban los planteos sobre la función social de la arquitectura que habían sostenido las vanguardias arquitectónicas en los años 20, sobre todo en su experiencia pedagógica más importante, la Bauhaus. Así, se indicaba que

"la firme convicción de que es necesario replantear críticamente el rol del arquitecto, la concepción de la arquitectura que lo determina y su enseñanza aquí y ahora, ha impulsado a docentes y alumnos de la Facultad (...), a asumirse como actores de un proceso que lleve a comprender la Arquitectura como práctica social, generada en la sociedad, interpretada interdisciplinariamente, asumida y resuelta por el arquitecto, y donde el USUARIO es su destinatario, continuador y hacedor en comunidad del producto: el hábitat humano",

para luego agregar que

"lo que se propone en última instancia [el TT], es el reemplazo de una práctica y enseñanza fundadas en un eje técnico-estético por una estructura orientada por el eje científico-social. Científico, en tanto entraña el conocimiento real de nuestros problemas, referidos al quehacer específico del arquitecto. Social, en tanto no puede separarse el conocimiento de la solución efectiva, profunda y radical que deba darse a esos requerimientos". ${ }^{66}$

De tal manera, la arquitectura era entendida como una práctica social que, además, requería del auxilio de las ciencias sociales -lo que llevó a la incorporación de un grupo de cientistas sociales a la Facultad.

\section{La dinámica de funcionamiento del Taller Total}

En cuanto a la dinámica de funcionamiento del TT hay que señalar varias cosas. En primer lugar, se puso en funcionamiento una comisión -integrada por docentes y estudiantes- encargada de analizar los problemas del curso lectivo de 1970 y de proponer soluciones a los mismos, pidiéndose la prórroga del ciclo

\footnotetext{
${ }^{65} \operatorname{RD} 148 / 70$ (22/9/70).

${ }^{66}$ Libro Mostaza, cit., pp. 7-8.
} 
lectivo hasta marzo del año siguiente que, finalmente, se extendió hasta julio. ${ }^{67}$ A esto se le sumó la creación de una comisión que, en base a los lineamientos del TT, debía encarar una reformulación del Plan de Estudios. ${ }^{68}$ En segundo lugar, como indicamos, en oposición a la idea de taller vertical que se sostenía en base a una estructura jerárquica muy bien definida, el TT pretendía una integración holística de la arquitectura por medio de una estructura que articulara en sentido horizontal y vertical las diferentes áreas de conocimiento en que se había dividido la estructura curricular, eliminando el anterior sistema de cátedras. Esto implicaba un trabajo conjunto de todos los niveles -vertical-, junto a una integración de cada campo de conocimiento -horizontal. El TT se organizaba en un área de "instrumentación" y otra de "síntesis". En esta última debían convergir los ejercicios de las sub-áreas, entendiendo que allí se llevaba adelante el "proceso de diseño". Por otro lado, el área de instrumentación se dividía en seis sub-áreas: Morfología; Metodología; Equipamiento; Ciencias Sociales (historia crítica del hábitat, sociología, antropología, economía); Tecnología; Practicanato de obra. En tercer lugar, el TT se dividía entre un “Taller Básico", puesto en funcionamiento en 1971, y el "Taller Total". El primero comprendía a primer año, mientras que el segundo al resto de los niveles. ${ }^{69}$ Durante 1970 y 1971 funcionó el "Taller de elementos de Arquitectura" hasta su reemplazo por el Taller Básico. En cuarto lugar, si el TT se organizaba en sentido horizontal por áreas de conocimiento, en sentido vertical estaba compuesto por doce Talleres, o "Equipos de Trabajo" (ET). Cada uno de los cuales tenía una coordinadora docente-estudiantil, integrada por nivel e internivel que, a su vez, debían confluir en una Coordinadora General que, en los hechos, era el máximo órgano de gobierno de la Facultad.

Esta dinámica de funcionamiento, si bien al principio podía presentarse como caótica en el trajín cotidiano de asambleas y discusiones, reflejaba una amplia participación que, como práctica política, se asentaba en la participación y el "anti-autoritarismo", entendido en su contexto, como un rechazo de las formas políticas tradicionales y verticales asociadas a las diversas "burocracias" (sindical, estudiantil, docente). En tal sentido, en la mesa redonda en la que se discutieron los alcances y problemas del TT, Mario Forné podía sostener, sin que alguien lo contradijera, que "el TT nace como producto de la revolución antiautoritaria, que no es producto de Córdoba, sino que es un producto internacional, del cual nosotros tenemos esta versión especifica y muy clara que se llama Taller Total".$^{70}$ Es necesario destacar que esta impronta anti autoritaria debe ser inscripta en un horizonte más amplio en donde las prácticas políticas

\footnotetext{
${ }^{67} \operatorname{RD} 142 / 70$ (14/9/70), RD 145/70 (17/9/70), RD 150/71 (14/7/71).

${ }^{68}$ La comisión estuvo integrada por Nilda Ramacciotti de Silvestre, Benjamín Elkin, Fernando Gomez, Raul Ferreira Centeno, Oscar Moraña, Isaac Edelstein, Santiago Kunzel, Edgardo Nizzp, Osvaldo Ramacciotti y María Saleme de Bournichón. RD 107/71 (13/5/71).

${ }^{69}$ Ordenanza 3/71 y 4/71 sobre el Taller Básico.

${ }^{70}$ El Taller Total, cit., p. 15.
} 
horizontales y de "base" tenían una amplia difusión en Córdoba -como en otro lugares del país-, como puede apreciarse en las experiencias clasistas de SitracSitram y del SMATA.

Las realidades y dinámicas de un taller a otro divergían notablemente. Algunos de ellos funcionaron con bastante éxito, llevando adelante diversas propuestas urbano-arquitectónicas, mientras que en otros, el clima de conflicto o de radicalización política hizo prácticamente imposible las tareas académicas. Al parecer, el "Taller once", en donde se encontraba Osvaldo Bidinost, fue el más politizado, con una presencia mayoritaria de militantes del PRT que, según recuerda Tito Chiavassa de las discusiones allí planteadas, sostenían que "hasta no cambiar el sistema capitalista no se puede hacer nada", lo que implicaba abandonar el diseño para dedicarse a la revolución. De acuerdo a diversos testimonios, si bien había militantes de todas las corrientes en cada taller, cada uno contaba con una presencia mayoritaria de una corriente política (maoísta, peronista, radical, anarquista, PRT, etc.). En algunos la convivencia era pacífica, en otros se presentaron numerosos problemas. Aunque cada taller funcionaba a partir de una coordinadora docente-estudiantil, cuyos delegados tenían mandato revocable, se reconocían ciertas figuras centrales que, además, solían ser las que daban la "orientación" política del taller. ${ }^{71}$

En pos de la transformación completa de la Facultad, el TT también avanzó en una reformulación del sistema de concursos y de la carrera docente. La nueva dinámica de concursos constaba de una prueba teórica -dividida en una instancia de discusión colectiva, en base a un tema sorteado, y en una exposición individual-, una prueba práctica individual sobre trabajos de alumnos y un periodo de prueba de seis meses que los confirmaría en el cargo. ${ }^{72}$ La primera tanda de concursos se realizó a principios de 1971, llamándose treinta y seis cargos de Jefes de Trabajos Prácticos. ${ }^{73}$ El tribunal estuvo integrado por Taranto, Mario Luis Corea, Juan Carlos Viotti, Benjamín Elkin y

\footnotetext{
${ }^{71}$ Escapa a las posibilidades de este trabajo el realizar una reconstrucción de los diferentes talleres y de quienes lo integraron, tarea complicada por las fuentes incompletas y por la dinámica misma del TT y de la coordinadora docente-estudiantil. A pesar de ello, y de modo tentativo con las información disponible -RD 72/73 y la información provista por varios entrevistados- ofrecemos la siguiente lista: Taller 1: Luis Cuenca; Taller 2: Fontán, Tito Chiavasa, Pistorio, Rojo (presencia del PCR y del peronismo); Taller 3: Fernando Gomez, Ferrero Centeno, Miguel Ángel Roca (presencia del PCR); Taller 4: Raúl Halac, Silvestre, Iróz (presencia del radicalismo); Taller 5: Celso pizzi; Taller 6 Arquímides Federico (presencia del peronismo); Taller 7: Violeta Huehara, Elkin, Lambertucci, Hobbs; Taller 8: Ricardo Veteri; Taller 9: Adolfo Nisman, Fativolo, Nizzo (presencia del PCR); Taller 10: Osvaldo Bontempo (presencia de Montoneros); Taller 11: Gerónimo Filippi, Bidinost (presencia del PRT); Taller 12: Ramacciotti.

${ }^{72}$ La RD 20 (5/2/71) establecía de forma provisoria el mecanismo de concursos, reafirmado con la Ordenanza 11/72.

${ }^{73} \mathrm{RD} 20$ (5/2/71).
} 
Edmundo Arias. ${ }^{74}$ En 1972 se llamó a concurso, al parecer, a más de cien cargos. ${ }^{75}$ A esta última tanda se presentaron Taranto, Pardina, Cuenca, Keismajer y Elkin, quienes habían sido cesanteados en 1966. Previamente, una de las primeras acciones de Fontán había sido declarar que los motivos por los que habían sido expulsados esos docentes no constituían impedimento para "futuras presentaciones a concurso". ${ }^{76}$ Según diversos entrevistados, si bien existió la voluntad de reintegrarlos desde un principio -como vimos, la demanda por su reincorporación estuvo presente en diversos momentos-, el problema era que la mayoría de ellos pretendía recuperar sus antiguos cargos, situación que, por diversos motivos, no era posible. La solución a la que llegaron fue que se presentaran a concurso, como lo hicieron algunos, mientras que el resto -Rébora, Hobbs- volvieron a la FAU recién en 1974, cuando se reincorporaron a todos los expulsados de las Universidades públicas desde 1946 por Ley Nacional. ${ }^{77}$ El tema es relevante porque demuestra, efectivamente, que el proceso de radicalización no se hizo en contra de quienes habían sido los actores centrales de la FAU en los tempranos 60, como sí ocurrió en otras disciplinas, como en el caso de Sociología de la UBA. Todo lo contrario, en nuestro caso el contexto de politización de los años 70 implicó una radicalización de los postulados que habían servido para la renovación disciplinar, por ello no debe sorprender que ese grupo de arquitectos y docentes quedaran como referencias privilegiadas. Si su incorporación al TT fue tardía se debió no solo a su expulsión previa de la Universidad, sino a que, en buena medida, el proceso alcanzó dimensiones no previstas, que volvieron extemporánea la cuestión.

De todas maneras, esto contrasta fuertemente con el trato recibido por la mayoría de los integrantes del antiguo Consejo Académico. Durante octubre de 1970 uno de los temas más discutidos fue qué hacer con ellos, en base a la propuesta del ET “D” que pedía su expulsión de la Facultad. Las posturas no eran uniformes en los distintos ET. Así, en el ET "C" -Cocatto y Gómez- se pedía que se discutiera en Asamblea del TT, en el ET "E" - de Pistorio y Crostelli- no hubo acuerdo; el ET "F" se pedía "negar la participación al TT del ex-Decano y el ex-Consejo Académico en virtud de su actuación anterior con respecto al gobierno de la FAU y el TT", igual posición fue tomada en el ET " $\mathrm{H}^{\prime}$ -Ramacciotti, Ruíz, Reartes-; mientras que en el ET "J" - Cragnolini, Ricci,

\footnotetext{
${ }^{74}$ RD 26/71 (18/2/71) y RD 58 bis (2/4/71).

${ }^{75}$ No hemos podido encontrar la Resolución Decanal de llamado a Concurso, aunque sí tenemos las de designación. La documentación, además de no estar completa, en muchos puntos es confusa, habiendo dos resoluciones de designación de concurso. En la primera se nombran 121 cargos, en la segunda a 35. RD 3 y 4/73. La Ordenanza 11/72 de llamado a concurso estipulaba solamente sesenta y cuatro cargos.

${ }^{76} \mathrm{RD} 149 / 70(22 / 9 / 70)$.

77 RR 1592/73.
} 
Rujinsky- se mocionaba para que no fueran expulsados, pero como parte de una postura que radicalizaba aún más la propia experiencia del TT:

"si la elección de víctimas propiciatorias [los ex miembros del consejo] obedece al criterio de atacar a quienes representan la política de las clases dominantes en la Universidad, parece obvio recordar que ella, en este momento, es ejercida por el Delegado Rectoral" ${ }^{78}$

Como indicamos, el TT también procedió a un cambio en la carrera docente. Según la propuesta del Libro Mostaza, se estipulaban cuatro "estadios" que iban desde el "adscripto" hasta el de "docente formado". Puesta en funcionamiento en octubre de 1972 durante el Decanato de Víctor Soria, ${ }^{79}$ la carrera docente implicó que las anteriores jerarquías docentes fueran eliminadas y substituidas por una división entre "docentes en formación" y "docentes formados".

Es necesario destacar dos cuestiones respecto a los concursos y la carrera docente. La primera es que las reformulaciones planteadas por el TT convivieron y se superpusieron a la legislación nacional vigente -incluso a disposiciones estatutarias de la UNC- que en nada contemplaban -o hasta se oponían- a lo resuelto por el TT. Esta situación, caótica en principio, parece haberse resuelto por un ágil e imaginativo trabajo de homologación por parte del personal administrativo de la Facultad. La segunda es que, si en principio había un acuerdo general en el espíritu de las reformas, algunas cuestiones entraban en conflicto con el reconocimiento del docente en cuanto trabajador, en el mismo momento en que se creaba el primer sindicato docente en la Facultad, la Asociación de Docentes de Arquitectura y Urbanismo. En la fundamentación de la Ordenanza sobre Carrera Docente del Libro Mostaza, se explicitaban estas tensiones, aunque no se llegaba a una resolución. Según se señalaba,

"la organización de este trabajo intelectual debe normarse en función del derecho y reivindicaciones de quienes lo practican, pero en modo alguno puede obstaculizar o contraponerse al interés de quienes estudian. (...) La no jerarquización docente contenida en la concepción del Taller Total, apunta a negar la jerarquía y el verticalismo impuesto pero en modo alguno puede oponerse a la necesaria evolución del docente en su capacitación específica y pedagógica". ${ }^{80}$

\footnotetext{
78 Boletín informativo del Taller Total, núm. 3 (21/10/70). Lamentablemente no hemos podido encontrar otros números de este boletín.

$79 \operatorname{RD} 135 / 72$ (9/10/72).

${ }^{80}$ Libro Mostaza, cit., pp. 77-78.
} 
En ese sentido, una comisión de docentes del Taller Básico dejaba constancia sobre las contradicciones sobre las que se avanzaba: "se parte de la contradictoria posición de suponer que toda reforma lleva implícita una optimación superadora del tema cuestionado", señalando algunos puntos problemáticos que se desprendían de los concursos: el más importante era que no "resolvía el problema económico real que se le plantea al concursante el cual tiene que dejar sus actividades por el lapso de un mes y medio", pero además "no supera el hecho competitivo sino que por el contrario este se traslada al taller", donde también se desvirtúa el control estudiantil "en tanto los alumnos no tendrán nunca una relación general y totalizadora de los concursantes sino parcial y esquemática" ${ }^{81}$

\section{Nuevas prácticas urbano-arquitectónicas en el Taller Total}

Puestos a redefinir el rol del arquitecto y de la arquitectura, preocupados por su compromiso social, interesados en reconocer un papel activo del usuario en el proceso de diseño, era razonable que se intentara salir de las aulas, que se procurara "sacar la Facultad a la calle". De tal forma, durante el desarrollo del TT se llevaron adelante, aunque de forma inorgánica e incipiente, lo que uno de los protagonistas recuerda como "nuevas prácticas políticas urbano arquitectónicas". ${ }^{82}$ En este apartado describiremos algunos episodios que hemos podido recuperar. Si bien es cierto que este tipo de actividades no fueron generales ni sostenidas en el tiempo, señalan uno de los costados más interesantes del TT, así como uno de los menos recordados.

Tal vez una de las primeras actividades que apuntaba a analizar las condiciones de vida y las necesidades de los habitantes se realizó en el marco del Taller de Elementos de Arquitectura. En la propuesta de trabajo, se les pidió a los estudiantes que analizaran las características socio-económicas, culturales y arquitectónicas de diversos barrios. Para acentuar la comparación, se eligieron barrios intermedios de clase media (Santa Ana, Parque Vélez Sarsfield y Alta Córdoba) y periféricos de clases populares (Villa El Libertador, Santa Isabel y Las Violetas). Esto supuso un desplazamiento a los sitios y recolección de información en el lugar. ${ }^{83}$

Si bien las experiencias eran diferentes de acuerdo a la dinámica de cada Taller, hubo un intento general de vincularse con la ciudad y los barrios. En esa línea, según relata Chiavassa, se realizó un relevamiento del Barrio Sud, detectando problemas de déficit edilicio, información que luego fue entregada

\footnotetext{
${ }^{81}$ Documento "E50", núm. 1 "Aporte de la Comisión de docentes del taller básico para la discusión de los concursos", fechado el 23/9/71.

82 Entrevista Tito Chiavassa.

83 "Conclusiones de Talleres del T.E.A. sobre comparación entre barrios", FAU, Córdoba, junio de 1971.
} 
al SMATA. ${ }^{84}$ Pero, sin dudas, una de las experiencias más relevante fue la organizada por Juan "Negro" Tarter en un pueblo del noroeste de Córdoba, Villa de Soto, entre 1974 y 1975. Según recuerda Tarter, a partir de un convenio con la Municipalidad -manejada por el peronista Alberto Melo- para trabajar sobre temas de salud y vivienda, se realizó en el pueblo un primer congreso en 1974 en el que participaron alumnos y docentes de la FAU, que incluía una exposición con las propuestas de viviendas anti-chagásicas. En 1975 se realizó un segundo congreso en Soto, para retomar las propuestas de vivienda y avanzar con un reconocimiento urbano, pero en la interacción con los habitantes surgió como tema prioritario el problema del agua potable y el de la tenencia de la tierra, llegando a la conclusión de que el tema de la vivienda respondía a un problema cultural. Al parecer, también participó del encuentro Dante Schulman y un grupo de estudiantes de Buenos Aires. Allí se propuso crear una cooperativa ladrillera y se construyó un prototipo de vivienda. ${ }^{85}$

Una experiencia aún más politizada se dio en "Colonia Lola" -un barrio periférico de obreros pobres- en el que se trabajó desde el Taller once de Bidinost. El barrio tenía fuerte presencia de diversas agrupaciones políticas y, presumiblemente, Bidinost y sus alumnos llegaron ahí gracias a los contactos del PRT. De la poca información disponible, particularmente los recuerdos de Eduardo Lastra -estudiante en el momento-, se intentó avanzar con una "arquitectura participativa" que consistió en una interacción entre los estudiantes y los habitantes del barrio respecto a sus necesidades más inmediatas, principalmente la de una escuela y de un centro de salud. Los estudiantes propusieron mejoras en el diseño arquitectónico e introducir diferentes técnicas constructivas. Para ello armaron capacitaciones conjuntas con los albañiles de la zona, que se ofrecían a quienes quisieran participar de las actividades de autoconstrucción. ${ }^{86}$

El TT también dio lugar a una articulación más específica con el mundo de la política. En octubre de 1973, la FAU publicó Construcciones masivas con participación popular, una reproducción del trabajo realizado por la Juventud Universitaria Peronista, haciéndose eco de uno de los temas que habían circulado por el TT, el de la "autoconstrucción”. Allí se establecían criterios y definiciones sobre el rol del arquitecto y sus relaciones con los usuarios -en los que se establecía la necesidad de la "organización política de los usuarios para su activa participación en el proceso" de diseño-, en una suerte de "sistema de arquitectura para la participación popular". Según pudimos corroborar, gracias a los datos aportados por quien era en ese momento responsable del

\footnotetext{
${ }^{84}$ Comunicación del autor con "Tito" Chiavasa.

${ }^{85}$ Comunicación del autor con Tarter, 15/5/15. Ver también, Tarte, Juan, et al "Comprender la dinámica del taller total a través de la experiencia de soto" en $1^{\underline{0}}$ Encuentro Internacional "La Formación Universitaria y la Dimensión Social del Profesional", CD, UNC, Córdoba, 2015.

${ }^{86}$ Lastra, Eduardo “Taller Once - Colonia Lola" en $1^{\underline{o}}$ Encuentro Internacional, cit.
} 
"Movimiento Villero" y de la Juventud Peronista -dos de las ramas que componían Montoneros-, el tema de la "autoconstrucción" fue tomada de la experiencia del TT, en el marco de la problemática más general de la autogestión que manejaba el Movimiento Villero. La iniciativa fue discutida en las oficinas de la Dirección Nacional de Educación para Adultos de la Nación (DINEA), con representantes del TT y de los grupos Montoneros. Los apuntes armados por gente del TT comenzaron a usarse desde 1972 en la Villa Chacho Chico -en el sector noreste de la ciudad de Córdoba. Primero se intentó la creación de cooperativas de trabajo para luego construir un Centro Comunitario, un Dispensario de Salud y aulas para alfabetización. La misma publicación fue presentada ante el Ministerio de Bienestar Social -a cargo de José López Rega-, como parte de un proyecto nacional encarado por Montoneros que fue truncado por los enfrentamientos políticos del momento. Incluso se realizó un audiovisual para el Gobernador Ricardo Obregón Cano. Al parecer, solo allí se logró poner en práctica lo sostenido en la publicación del $\mathrm{TT}$, ya que la dinámica de los tiempos políticos impidió extender esta experiencia, en tanto la vuelta a la clandestinidad de Montoneros supuso el fin de su militancia de base. Justamente esta experiencia de autoconstrucción villera fue valorada como positiva, en una lectura que advertía sobre los problemas de la "militarización" de Montoneros, en el editorial del número 2/3 de la segunda época de Pasado y Presente ${ }^{87}$ Es interesante notar aquí cómo la propia radicalización disciplinar podía servir de vehículo para la radicalización política.

Estas diferentes prácticas político-arquitectónicas -reconstruidas parcialmente- dan cuenta del intento de poner en práctica la función social de la arquitectura, en el que la identificación de un "usuario" definía una problemática disciplinar específica, bajo el presupuesto que la arquitectura podía intervenir en los procesos de transformación social. Pero esto suponía una doble cuestión: por un lado, al interior de la disciplina se cuestionaba menos un saber técnico -eventualmente necesario para mejorar las condiciones de habitabilidad- que una actitud profesional en la que el arquitecto se reservaba la función de "creador de formas" -que la temática de la “autoconstrucción" venía a poner en entredicho-; por otro lado, hacía afuera

\footnotetext{
${ }^{87}$ Allí puede leerse: “Las movilizaciones obreras en las fábricas y el contenido de los reclamos que en ella aparecen; (...) las luchas por la vivienda, que plantean los grupos más avanzados del movimiento villero peronista, en las que el objetivo de la casa se plantea no como una dádiva del estado sino como una meta construida y controlada por quienes la reclaman; los planteamientos estudiantiles tendientes a superar el asilamiento de la Universidad y a vincular a los intelectuales con el mundo de la producción son, entre otros, indicadores elocuentes del nuevo rumbo que están tomando las movilizaciones de las clases populares" en Pasado y Presente "La crisis de julio y sus consecuencias políticas" en Pasado y Presente, núm. 2/3, Buenos Aires, julio-diciembre de 1973, p. 205. Agradezco a Ricardo Panzeta el haberme puesto al tanto de estos datos.
} 
del TT, permite ver las heterogéneas tramas y espacios en los que esta experiencia tuvo alguna incidencia, ya sea en las redes más radicalizadas -como Montoneros o el PRT ${ }^{88}$ o en espacios, en principio, alejados de las mismas, como en Soto. Estas cuestiones muestran, aunque sea en parte, la importancia que tuvo el TT en los años 70, indicando la necesidad de restituir a la arquitectura como parte de una historia cultural más amplia. En tal sentido, el TT señala que la radicalización no siempre implicó una pérdida de autonomía del campo intelectual -según la tesis de Sigal-, sino que igualmente dio lugar a experiencias que pretendieron recuperar el impulso modernizador de los años previos, llevándolo hasta sus máximas implicancias. Si en la propuesta de Sigal radicalización se entiende como interrupción de la modernización, aquí deberíamos hablar de una "aceleración". Aunque mucho de esta deriva responda a las especificidades de la disciplina arquitectónica, no deja de aportar a una mirada complejizadora del conjunto.

Más allá de estas cuestiones, para 1973, al tiempo que la experiencia se expandía por otras Universidades -como en la Plata- también lo hacía en otras disciplinas en Córdoba -como en la Escuela de Trabajo Social y en la de Artes-, el TT se enfrentaba a sus propias dificultades, derivadas de una intensa dinámica de asambleas y discusiones. El marco adverso que se dio para las experiencias universitarias de radicalización luego de 1974 -particularmente con la "misión Ivanissevich"- junto a la temprana represión en Córdoba, volvieron insostenible al TT. Antes de que tuviera que enfrentarse a sus propias contradicciones, el TT fue dado por terminado a finales de 1975 durante la intervención de Liliano Livi.

Córdoba, mayo de 2016

${ }^{88}$ La relación del TT con los grupos armados es un tema que merecería una atención aparte pero que, hasta el momento, no ha sido abordada. 